\title{
Study of microstrain and stress in non-planar Palladium membranes for hydrogen separation \\ Mariangela Brisotto ${ }^{1, a^{*}}$, Marcello Gelfi ${ }^{1, b}$, Claudia Rinaldi ${ }^{2, c}$, Laura E. Depero ${ }^{1, d}$
}

${ }^{1}$ DIMI (Department of Mechanical and Industrial Engineering), via Branze 38, University of Brescia, Italy

${ }^{2}$ RSE (Ricerca sul sistema Energetico) via Rubattino 154, Milan, Italy

amariangiola.brisotto@unibs,it, ${ }^{b}$ marcello.gelfi@unibs.it, ${ }^{c}$ claudia.rinaldi@rse-web.it,

laura.depero@unibs.it

Keywords: microXRD, microstrain, hydrogen, heat treatment

\begin{abstract}
MicroXRD measurements were performed to evaluate the effect of the stress-relief heat treatment, carried out for different time and temperatures on Palladium layers of tubular membranes used for hydrogen separation. Since residual stresses were not detected, the FWHMs were evaluated by the integration of the Debye rings and the microstrains calculated by the Williamson-Hall (W-H) equation. After the normalization for the elastic anisotropy (altered $\mathrm{W}-\mathrm{H}$ analysis), the data showed a very good linear behaviour.

The evolution of Pd microstructure was also studied and the best thermal profile for the heat treatment of the Palladium membranes was found.

\section{Introduction}

Hydrogen is one of the most studied energy new fuels in recent decades, is in view of its high calorific value [1]. Nowadays, the most economically convenient technology for hydrogen production is the steam reforming of methane, followed by water gas shift (WGS) reaction.

The separation of $\mathrm{CO}_{2}$ in Water Gas Shift (WGS) processes is through palladium tutular membranes and solution-diffusion mechanisms [2] at temperatures up to $400{ }^{\circ} \mathrm{C}$ [3]. To ensure high selectivity in the separation process, the $\mathrm{Pd}$ layer is usually deposited on the porous substrate. Its microstructure must have low defects and be free of residual stresses [4]. The optimization of membrane reactors is a condition for a competitive production of hydrogen.

Palladium is used in membrane reactors as it allows the selective diffusion of hydrogen through its structure by solution-diffusion mechanism. In the ideal Palladium structure, there is a full selectivity for hydrogen.

The aim of this paper it to analyze the tubular membranes by means of $2 \mathrm{D}$ microdiffraction. Preliminary results shown the possibility of using microdiffraction for the analysis of tubular membranes and the Williamson-Hall $(\mathrm{W}-\mathrm{H})$ analysis for the evaluation of the microstrains [5]. DRAST method [6] was used to evaluate the residual stress, that were not detectable, and the microstress were there evaluated by W-H equation [7]. The FWHMs of the integrated peaks were also normalized considering the elastic modulus of each family plane. Also the crystallization, that may change the mechanism of hydrogen diffusion and thus reducing the permeability [4], was evaluated.
\end{abstract}

\section{EXPERIMENTAL}

\section{Sample preparation}

The membranes were prepared in RSE S.p.A (http://www.rse-web.it/): commercial AISI 316L oxidized porous substrate, having roughness values of 3 and $0.3 \mu \mathrm{m}$, were coated with Palladium by electroless deposition. The layer thickness was between 10 and $40 \mu \mathrm{m}$ (see table 3). Helium permeance of the membrane was lower than $10^{-9} \mathrm{~mol} / \mathrm{m}^{2} / \mathrm{sec} / \mathrm{Pa}$. Each membrane was treated at 400 ${ }^{\circ} \mathrm{C}$ with different thermal profiles. 


\section{Characterization techniques \\ SEM FEG}

The surface morphology of Palladium was examined in a scanning electron microscope SEM FEG MIRA 3 - TESCAN with Energy Dispersive Spectroscopy (EDS) X-ray microanalysis.

\section{XRD}

XRD images were acquired by a Rigaku D-Max Rapid microdiffractometer $(\mathrm{Cu}$ tube $-40 \mathrm{kv}$ and $30 \mathrm{~mA})$ with $\mathrm{CuK} \alpha$ radiation $(40 \mathrm{kV}$ and $30 \mathrm{~mA})$. This system is equipped with an cylindrical Image Plate detector; the range was from $-45^{\circ}$ to $160^{\circ}(2 \theta)$ horizontally and from $-45^{\circ}$ to $+45^{\circ}(2 \theta)$ vertically. The collimator diameter was of $300 \mu \mathrm{m}$.

Specimens were housed on the specially designed sample holder. The geometry of the experiment and test parameters are shown below. The measurements were performed in reflection condition with the incident angle of $10^{\circ}$ degree. The exposition time was 30 minutes.
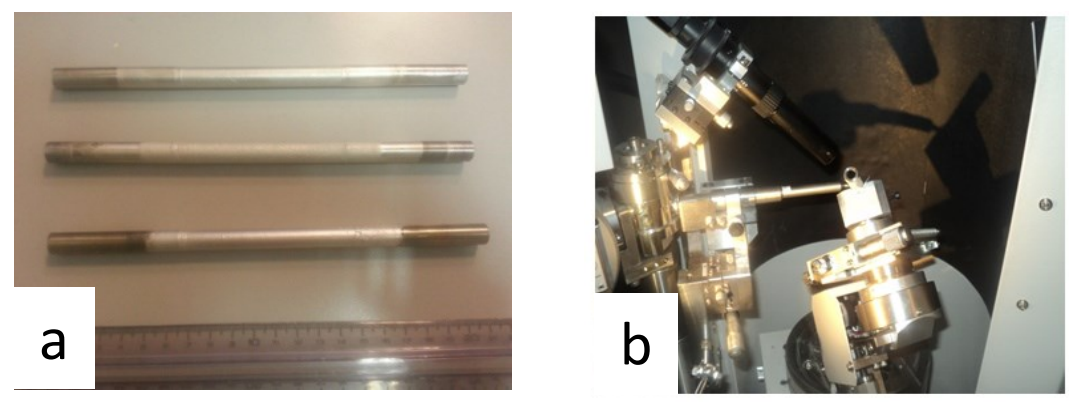

Fig.1. $\quad$ Examples of membranes (a) and experimental set-up (b)

\section{RESULTS AND DISCUSSION}

SEM images of samples before the thermal treatment showed fractal growth with cauliflower morphology typical of Pd coatings obtained with the electroless technique (see Fig.1)

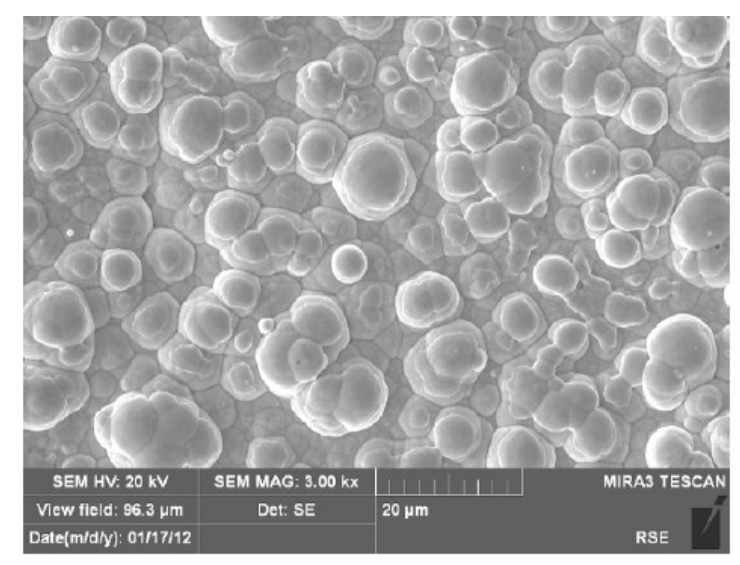

Fig.1. Typical SEM image showing the Pd morphology

For the analysis of the residual stress, the DRAST method was applied [6]. This method is suitable for the stress analysis of coatings of sample with complex geometry. When the sample is stress-free, the peak position along the Debye ring is the same in all directions. On the contrary, if the peak maximum depends on the direction, the strain can be evaluated. Indeed, the distortion of the Debye ring is due to the different strains of the corresponding crystallographic planes. The $2 \theta$ values at different $\psi$ angle obtained from the analysis of XRD integrated patterns can be used in the classic $\mathrm{d}-\sin ^{2} \psi$ plot to calculate the stress. Any residual stress were detected in the considered Pd membrane. 
Images were then integrated, after subtraction of constant background. The decreasing of the Full Width of the Half Maximum (FWHM) of the peaks can be related to reduction of the average microstrain and/or to the increasing average dimension of the crystallites.

The Williamson Hall equation [7] [8] [9] was used to evaluate these parameters:

$$
\beta \cos \theta=\frac{k \lambda}{t}+4 \varepsilon \sin \theta
$$

where $\beta$ is the FWHM of the hkl reflection, $\mathrm{k}$ is the Scherrer's constant, $\mathrm{t}$ is the average crystallite dimension, and $\varepsilon$ is the microstrain.

The FWHMs of $111,200,220,311,222$, and 400 reflections were evaluated and corrected by subtracting the instrumental broadening of the $\mathrm{LaB}_{6}$ standard powder.

The percentage of reduction of microstrains after the thermal treatment was calculated according to the equation:

$$
\Delta \varepsilon \%=\frac{\varepsilon_{\text {before }}-\varepsilon_{\text {affer }}}{\varepsilon_{\text {before }}} \times 100
$$

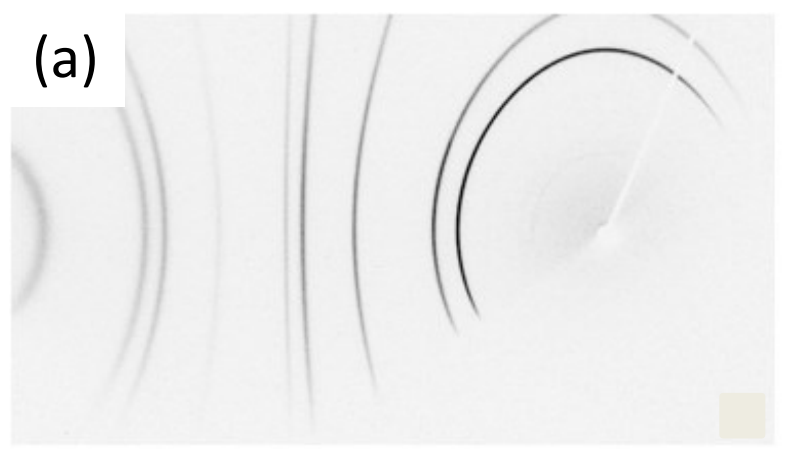

(b)

Fig.2. Typical XRD images obtained by the membranes before (a) and after (b) heat treatment

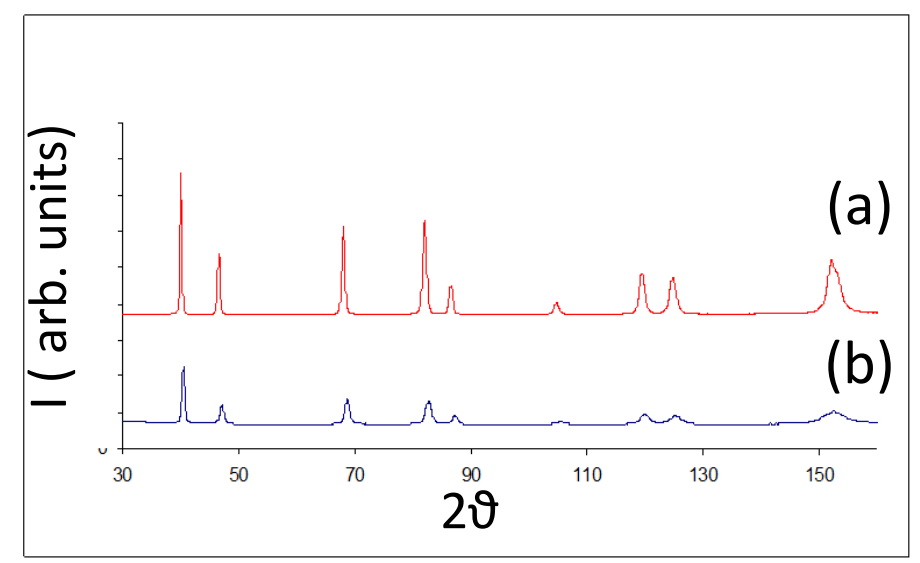

Fig.3. Typical integrated spectra before ( a) and after (b) heat treatment

To take into account the anisotropy of the crystal elastic properties, the correction of the Williamson-Hall law was proposed for copper and nickel [10], that are isostructural to Palladium by using the following equation:

$$
\delta_{h k l}=\frac{\varepsilon_{h k l}}{E_{h k l}}
$$


By the same approach, the values of the obtained microstrains for Pd membrane were normalized by Young's moduli. The value of the Young's modul for each family plane has been calculated [11] and reported in Table 1:

Table 1: Young's moduli of (hkl) planes

\begin{tabular}{|cc|}
\hline $\mathbf{h k l}$ & $\mathbf{E}$ (MPa) \\
100 & 11.02 \\
111 & 16.96 \\
110 & 11.97 \\
311 & 12.53 \\
\hline
\end{tabular}

In Figure 4 the good linearity obtained in the modified Williamson Hall plot is shown.

Table 3 reported the characteristics of the analyzed membranes.
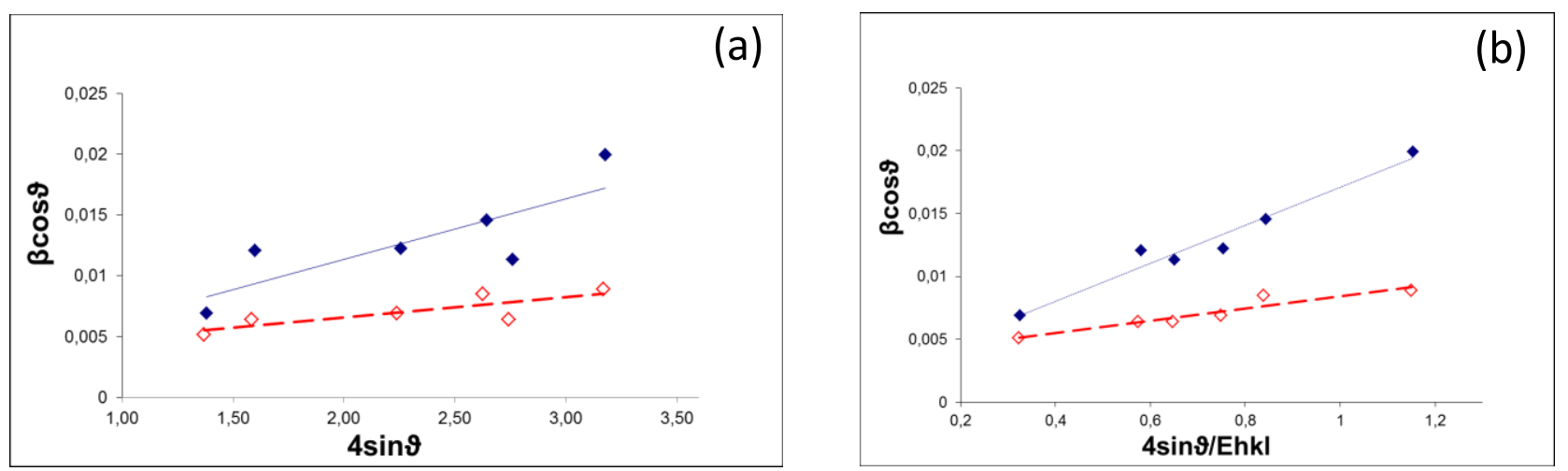

Fig.4. Typical linear fitting of $\beta \cos \vartheta$ against $4 \sin \vartheta$ (a) or $4 \sin \vartheta / E h k l$ (b): it is observed a decrease of the angular coefficient before treatment and after treatment (dotted lines)

Samples with different roughness and thickness were compared. Microdiffraction measurements were performed before and after the thermal treatment.

Before the thermal treatment, continuous Debye rings were obtained for all the samples. Thus, the coatings were polycrystalline and no preferred orientation was detected. However, the Debye rings of some membranes after the thermal treatment were discontinuous, suggesting a crystallization of the Pd phase.

All the membranes were thermal treated. The treatment should avoid the crystallization and the crystallites growth, that causes the change from interstitial to grain boundary diffusion. Four different heat treatments were performed (Tab.2). The microdiffraction results allowed to identify the optimum temperature profile.

In Table 3 it is shown that $\Delta \varepsilon / \varepsilon \%$ values decrease after thermal treatment, higher in the substrates with low roughness.

Table 2 Thermal Treatments (TT) conditions

\begin{tabular}{|cccc|}
\hline treatment & sample & $\begin{array}{r}\text { Temperature gradient } \\
\left({ }^{\circ} \mathrm{C} / \mathrm{min}\right)\end{array}$ & $\begin{array}{c}\text { Time at } 400^{\circ} \mathrm{C} \\
(\mathrm{h})\end{array}$ \\
\hline $\mathrm{A}$ & 4 e 5 & $0.3^{\circ} / \mathrm{min}$ & 15 \\
\hline $\mathrm{B}$ & 6 & $1 \% / \mathrm{min}$ & 15 \\
\hline $\mathrm{C}$ & $1-2-3-7$ & $1 \% / \mathrm{min}$ & 1 \\
\hline $\mathrm{D}$ & $8-9-10-11$ & $0.3^{\circ} / \mathrm{min}$ & 1 \\
\hline
\end{tabular}


Table 3: Samples characteristics and obtained results. " $R$ " means high roughness ( $R$ a and $R z$ of about $3 \mu \mathrm{m}$ and $17 \mu \mathrm{m}$, respectively), while " $L$ " means low roughness ( $R$ a and $R z$ of about $0.3 \mu \mathrm{m}$ and $3 \mu \mathrm{m}$, respectively). The suffix "TT" means thermal treatment.

\begin{tabular}{lccccc}
\hline sample & Substrate & Palladium thikness $(\boldsymbol{\mu m})$ & TT & cristallization after TT & $\Delta \varepsilon / \varepsilon \%$ \\
1 & R & 20 & C & NO & 47 \\
2 & R & 15 & C & NO & 59 \\
3 & R & 19 & C & NO & 50 \\
4 & R & 40 & A & NO & 49 \\
5 & L & 26 & A & YES & 80 \\
6 & L & 38 & B & YES & 43 \\
7 & L & 10 & C & NO & 56 \\
8 & L & 10 & D & NO & 66 \\
9 & L & 10 & D & NO & 49 \\
10 & L & 15 & D & NO & 62 \\
11 & Alumina & 15 & D & NO & 71 \\
\hline
\end{tabular}

The best treatment was found to be treatment $\mathrm{C}$ and D. Heating gradient, based on economic and timesaving reasons, was chosen to be $0.3{ }^{\circ} \mathrm{C} / \mathrm{min}$ (D profile in Table 2) .

\section{Preparation of the test sample for the pilot plant}

On the basis of the obtained results, the optimal values of parameters were selected to prepare a membrane to test, (sample G), with the minimum Palladium thickness $(10 \mu \mathrm{m})$ and low roughness substrate.

Helium permeance of this membrane was measured. The obtained value was $1.8^{*} 10^{-10} \mathrm{~mol} / \mathrm{s} / \mathrm{m}^{2} / \mathrm{Pa}$, more than one order of magnitude less than those previously produced.

After performing the thermal treatment D, the sample was named GTT, while after the functional test GTT after use.
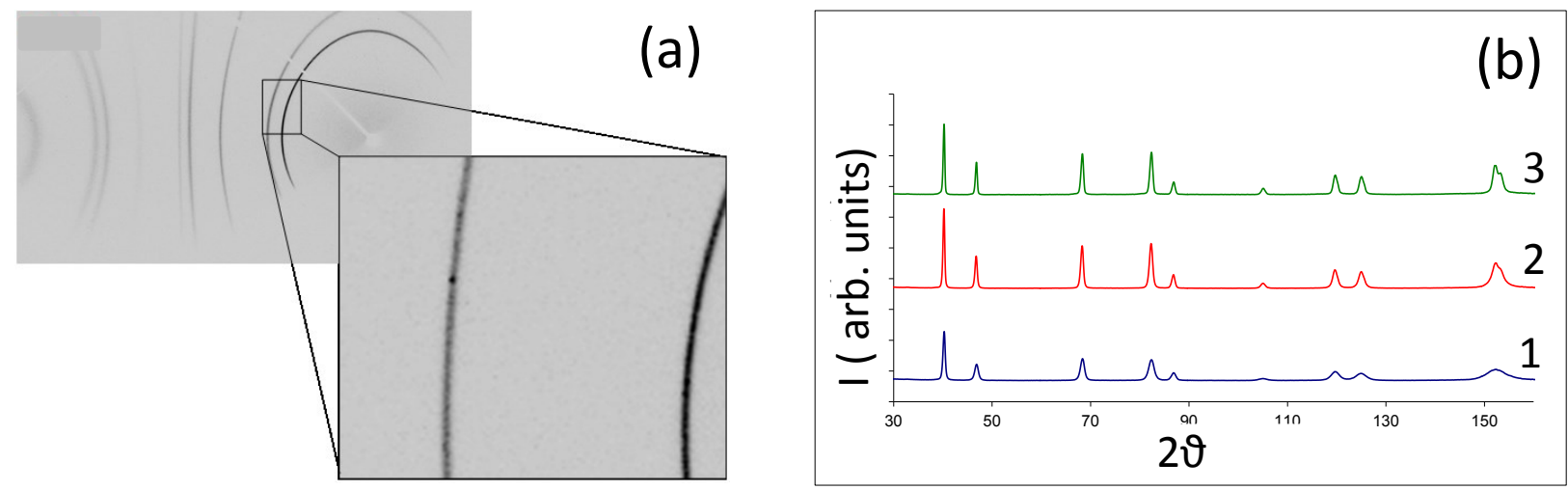

Fig.5. Membrane G4: (a) 2D image of the test sample after the thermal treatment. In the enlarged detail we observe weak spots suggesting the formation of large crystallites; (b) integrated spectra of test sample before TT (1) after TT (2) and after the functional test (3). The crystallization is shown by the narrowing of the peaks. 

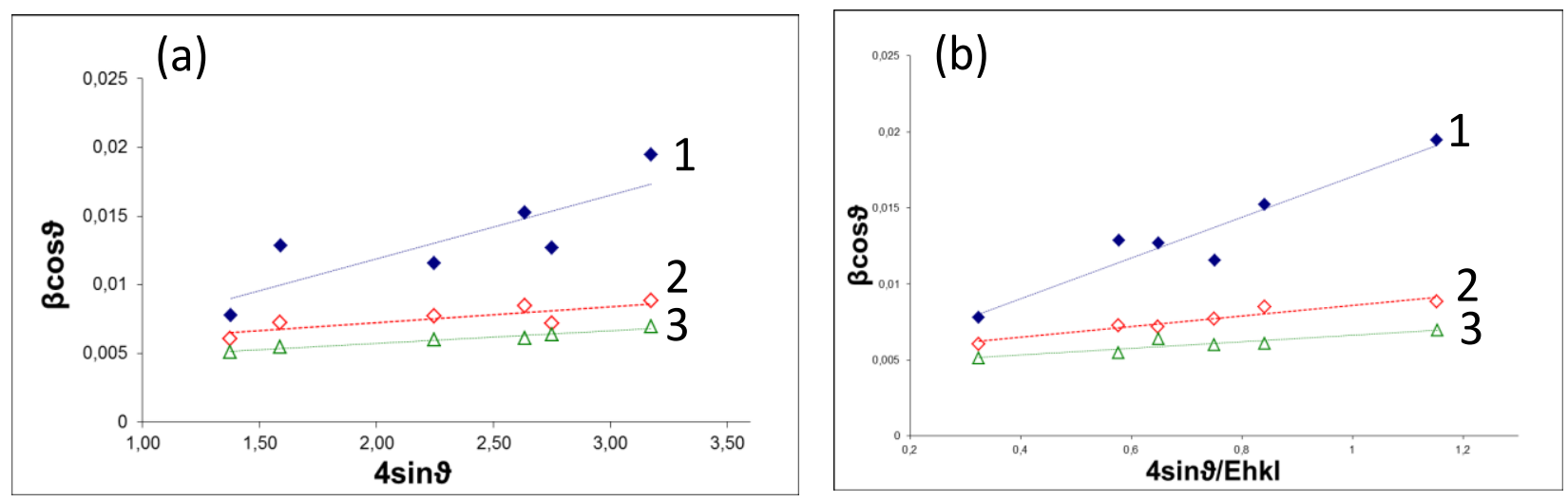

Fig.6. Linear interpolation of data with the W-H equation (a) and with the modified W-H equation (b). The angular coefficient after TT (2) and after the functional test (3) is lower then before TT (1)

\section{CONCLUSIONS}

The aim of this research was the optimization of Palladium membranes used for the separation of hydrogen from gas mixture obtained by WGS. The study of microstrains by means of X-ray diffraction has contributed to a better understanding of the membrane at the microstructural level. The functional and morphological results were correlated to the microXRD analysis. Four thermal treatments were carried at yhe working temperature $\left(400^{\circ} \mathrm{C}\right)$ on substrates of two different roughness. The possibility of microXRD to analyze goods with complex geometry, as tubular membranes, allowed to identify the optimum temperature treatment on the real component.

This work has been financed by the Research Fund for the Italian Electrical System under the Contract Agreement between RSE S.p.A. and the Ministry of Economic Development - General Directorate for Nuclear Energy, Renewable Energy and Energy Efficiency stipulated on July 29, 2009 in compliance with the Decree of March 19, 2009

\section{References:}

[1] "Hydrogen and fuel cells" edited by Detlef Stolten, Wiley-VCH, 2010

[2] S. Yun, S. T. Oyama "Correlations in Palladium membranes for hydrogen separation: a review" Journal of Membrane Science, 375, 28-45 (2011)

[3] P Pinacci, M. Broglia, C. Valli, G. Capannelli, A.Comite, "Evaluation of the water gas shift reaction in a Palladium reactor" Catalysis Today, 156, 165-172 (2010)

[4] F. Guazzone, E. A. Payzant, S. A. Speakman, Y. H. Ma "Microstrain and stresses analysis in electroless deposited thin Pd films" - Ind. Eng. Chem. Res., 45, 8145-8153 (2006)

[5] M. Brisotto, L.E. Depero, M. Broglia, C. Rinaldi, “ Evoluzione della microstruttura e dei microstrain dello strato funzionale in membrane dense per la separazione dell'idrogeno", La Metallurgia Italiana, n.11-12, 2013

[6] M. Gelfi, E. Bontempi, R. Roberti, L.E. Depero, "X-ray diffraction debye Ring Analysys for Stress measurement (DRAST): a new method to evaluate residual stresses", Acta Materialia, 52,583-589 (2004)

[7] G. K. Williamson, W. H. Hall, "X-ray line broadening from filed aluminium and wolfram", Acta Metallurgica, 1, 22-31 (1953)

[8] E. J. Mittermeijer and Udo Welzel, " The "state of art" of the diffraction analysis of crystalline size and lattice strain”, Z. Kristallogr, 223, 552-560 (2008)

[9] A. K. Zak, W.H.A. Majid, M.E. Abrishami, R. Yousefi, Solid State Science, 13, 251-256 (2011) [10] R. K. Islamgaliev, F. Chmelik, R. Kuzel, “ Thermal stability of submicron grained copper and nickel", Materials Science \& Engineering, A237, 43-51 (1997)

[11] ] B. D. Cullity, "Elements of X-ray Diffraction", AddisonWesley Publishing Company, Inc. (Reading, MA, USA) 1978. 